\title{
$O$ agir em competência para o cuidado especializado na saúde bucal
}

Cristine Maria Warmling; ${ }^{*}$ Julio Baldisserotto**; Julia Stocker ${ }^{* * *}$; Daniele Benedetti Gallo**; Luciane Maria Pezzato ${ }^{* * * *}$; Fernando Neves Hugo ${ }^{* * * * *}$

* Doutora em Educação, Docente no Departamento de Odontologia Preventiva e Social Faculdade de Odontologia - UFRGS

** Doutor em Gerontologia, Docente no Departamento de Odontologia Preventiva e Social Faculdade de Odontologia - UFRGS

*** Acadêmicas da Faculdade de Odontologia - UFRGS

**** Doutora em Saúde Coletiva, Docente da Faculdade de Odontologia da PUC-Campinas/SP

***** Doutor em Odontologia, Docente no Departamento de Odontologia Preventiva e Social Faculdade de Odontologia - UFRGS

\section{RESUMO}

O estudo possui o objetivo principal de ampliar a compreensão sobre a produção do "agir em competência” para o cuidado especializado na atenção à saúde bucal. A abordagem metodológica utilizou análises qualitativas e quantitativas. Um questionário online com 32 questões organizadas em cinco blocos temáticos foi respondido de forma anônima por estagiários de Odontologia nos serviços do Sistema Único de Saúde. Categorias temáticas e componentes analisadores foram sistematizados: protocolos, campos de estágio, atividades de educação à distância e dinâmicas pedagógicas. Os dados quantitativos foram analisados pela freqüência das respostas fechadas. Com relação às questões abertas o objetivo foi analisá-las procurando alcançar o sentido e não apenas o conteúdo do texto. Os resultados evidenciaram que a experiência de integração ensino-serviço analisada está proporcionando aprendizagens significativas sobre o funcionamento das redes de atenção especializada em saúde bucal e o desenvolvimento de competências para a resolução de problemas. A modificação de protocolos da atenção especializada em saúde bucal é uma experiência constante vivenciada pelos estagiários nos campos de estágio. Os aspectos da experiência com maior potencial inovador, político e pedagógico (os campos de gestão, as tutorias e a educação à distância) foram também os que apresentaram maior fragilidade.

Descritores: Saúde Bucal. Educação. Educação Baseada em Competências. Currículo. Educação Odontológica.

\section{INTRODUÇÃO}

Uma complexa conjuntura de acontecimentos vem pautando mudanças na organização do trabalho e dos processos de formação dos cirurgiões-dentistas brasileiros. Mas, esta não é uma realidade isolada do Brasil, autores de diversas partes do mundo têm explanado sobre esse panorama de modificações $^{1-4}$. As Diretrizes Curriculares Nacionais para os cursos de Odontologia, adotadas em 2002 no Brasil ${ }^{5}$, se originam do movimento mundial de transformações da prática odontológica. As marcantes mudanças demográficas e epidemiológicas estão incidindo nos processos de trabalho e contribuído para as 
suas alterações ${ }^{1,6}$.

O conceito de competência profissional emergiu com força no novo panorama de qualificação para o trabalho e se estabeleceu também como eixo central nos processos de ensino odontológico. Mudanças na organização no mundo do trabalho deslocaram o conceito de qualificação profissional presente na ótica taylorista-fordista para o de competência, renovando as bases das relações de trabalho e de educação ${ }^{7}$. As instituições brasileiras de ensino odontológico viram-se provocadas a integrar nos percursos de formação, atividades acadêmicas ligadas ao mundo do trabalho no Sistema Único de Saúde (SUS). Há consenso de que a integração do ensino ao serviço promove o aprendizado da responsabilidade social, considerada como uma das competências desejáveis aos perfis profissionais de cirurgiões dentistas na atualidade. Defende-se o importante papel das instituições brasileiras de ensino superior na contribuição para a diminuição das disparidades de acesso aos serviços odontológicos ${ }^{6,8,9}$.

Os movimentos de mudança na formação dos profissionais da saúde no Brasil, com a inserção no mundo do trabalho de estudantes de graduação, já vem ocorrendo desde a década de 1960, mas com mais intensidade após a promulgação da Constituição de 1988, que designou ao SUS orientar a formação dos profissionais da saúde ${ }^{10}$.

Em se tratando das políticas públicas brasileiras no âmbito da saúde bucal contatase que, tradicionalmente, foi priorizado o desenvolvimento de serviços no nível primário da atenção à saúde. Recentemente, porém, o Ministério da Saúde - com o objetivo de ampliar e qualificar o cuidado à saúde bucal da população brasileira - está desenvolvendo uma política nacional que incentiva a criação de Centros de Especialização Odontológica $(\mathrm{CEO})^{11,12}$. Esta política representa um esfor- ço para atuar com a mudança de perfil de complexidade das necessidades de tratamento odontológico da população brasileira.

A incorporação de vivências no nível da atenção especializada para contribuir nas reconfigurações das redes de atenção em saúde bucal que compõem o SUS, é um dos desafios das instituições de ensino odontológico para integrar-se aos serviços de saúde. Em consenso com as políticas e realidades atuais a Faculdade de Odontologia da Universidade Federal do Rio Grande do Sul vem desenvolvendo, desde o ano de 2009, o Estágio Curricular Supervisionado II da Odontologia. A implantação desse estágio foi acompanhada pela adesão da instituição de ensino ao Programa Nacional de Reorientação da Formação Profissional em Saúde (Pró-Saúde I e II). O estágio possui a meta de desenvolver competências profissionais para o trabalho na atenção especializada e hospitalar em saúde bucal, assim como em serviços de gestão do SUS $^{13}$.

O objetivo principal desse artigo é analisar as opiniões de estagiários sobre o Estágio Curricular Supervisionado II da Odontologia do Curso de Odontologia da Universidade Federal do Rio Grande do Sul desenvolvido, entre março e julho de 2013, em serviços do SUS. Estes serviços são responsáveis pelos níveis de gestão, atenção especializada e hospitalar na saúde bucal. Mas, há um sentido muito preciso em se proceder a análise aqui realizada, que se constitui em compreender o papel dos protocolos ${ }^{14}$ na produção de um "agir em competência"15 para o cuidado na atenção especializada em saúde bucal. A reflexão sobre uma experiência de integração ensino e serviço foi usada como mote para melhor compreender como se estabelecem as relações entre o que é prescrito pelo mundo acadêmico e científico e a realidade encontrada no processo de tra- 
balho na saúde bucal e como isso pode se desdobrar no agir em competência de futuros cirurgiões-dentistas e de trabalhadores do SUS.

O termo "integração ensino e serviço" possui diferentes conotações, mas de um modo geral pode ser compreendido como uma experiência de aprendizado estruturada que combina serviço comunitário com preparação e reflexão. Os estudantes ofertam serviços necessários à comunidade e aprendem sobre o contexto em que eles são ofertados. Essas experiências proporcionam ganho no aprendizado acadêmico do papel que possuem como cidadãos. O principal diferencial da integração ensino-serviço em relação a outras experiências de aprendizado é que este possui ênfase igualitária do foco no serviço e no aprendizado $^{16}$.

No Brasil, as políticas de reformulação curricular dos cursos de Odontologia determinam a priorização pelos cursos de Odontologia de experiências de integração ensino-serviço ${ }^{13,17-20}$. Contudo, a tendência de aumentar o tempo de estudantes de Odontologia atuando em programas comunitários não é uma preocupação apenas do Brasil, mas mundial ${ }^{16,21-24}$.

As Diretrizes Curriculares Nacionais para os cursos de Odontologia redefinem a importância do estágio curricular supervisionado nos percursos de formação do cirurgião dentista ${ }^{5}$. Porém é a Lei Federal $\mathrm{N}^{\circ} 11.788$, de 25 de setembro de 2008 que regulamenta a organização dos estágios estudantis. Esta lei determina que o estágio é ato educativo escolar supervisionado, desenvolvido no ambiente de trabalho, que visa à preparação para o trabalho produtivo de educandos que estejam frequentando o ensino regular em instituições de educação. Visa o aprendizado de competências profissionais e à contextualiza- ção curricular, desenvolvendo o educando para o trabalho ${ }^{25}$.

O estágio como parte intrínseca do projeto pedagógico do curso de graduação deve agregar as experiências de integração ensino-serviço planejadas no itinerário formativo, com o objetivo de desenvolver o "agir em competência” dos estagiários. O conceito de "agir em competência” é proposto com o objetivo de superar as dificuldades de articular todas as dimensões (heterogêneas) pertinentes a qualquer processo de trabalho. A noção de competência remete a pensar que aquilo que uma pessoa coloca em ação no trabalho não se restringe apenas a extensão protocolar do processo de trabalho ou ao que se considera como prescrito para a situação de trabalho. Muitas das dimensões da experiência humana na atividade de trabalho são subjetivas e, portanto, não mensuráveis. A atividade tem algo de sempre indefinível na medida em que ela é sempre micro "re-criadora" 15.

Pensando um processo formativo que leve em conta o conceito do "agir em competência”, durante a formação do estudante de Odontologia, deve ser proporcionado ao estudante vivencias que permitam atuar e apreender as diversas dimensões da atividade de trabalho: a apropriação de normas antecedentes que estruturam o trabalho (os protocolos), o domínio do que uma situação sempre possui de histórico e de inédito, assim como a capacidade de gerir esse inédito sempre presente quando a pessoa é remetida a tomar decisões $^{15}$. O estágio supervisionado é um espaço curricular em que naturalmente estas dimensões articulam o prescrito e o real.

\section{METODOLOGIA}

As atividades do Estágio Curricular Supervisionado II da Odontologia da Faculdade de Odontologia da Universidade 
Federal do Rio Grande do Sul, objeto dessa pesquisa, são desenvolvidas pelos estudantes do último semestre do curso de Odontologia. Perfazem um total de 465 horas/aula, sendo distribuídas em sete turnos semanais. Os estágios são realizados nos serviços de atenção especializada, hospitalar e de gestão das políticas de saúde bucal do SUS, nos níveis municipal e estadual (CEO dos Municípios de Porto Alegre e Alvorada, Serviço de Odontologia do Departamento Municipal de Água e Esgoto, Serviço de Estomatologia do Hospital das Clínicas de Porto Alegre, Instituto da Criança com Diabetes, Hemocentro do Estado do Rio Grande do Sul - HEMORGS, Área Técnica de Saúde Bucal da Secretaria Estadual do Rio Grande do Sul, Departamento de Ações em Saúde do DAS/SESRS, Coordenação de Saúde Bucal da Secretaria Municipal de Porto Alegre e Centro de Especialidade Odontológica da UFRGS, CEO do Grupo Hospitalar Conceição). Utilizam-se para isso cinco turnos semanais para que os estagiários atuem sempre com o acompanhamento e a orientação de um cirurgião-dentista denominado de preceptor ${ }^{26}$, o qual possui o papel na inserção e socialização do estagiário ao ambiente de trabalho.

Semanalmente ocorre também um turno de encontro presencial na Faculdade de Odontologia com a orientação de docentes, em que se desenvolvem debates temáticos, apresentação de seminários, relatos, apresentação e discussão de situações vivenciadas no estágio, oficinas de integração ensinoserviço-comunidade, apresentação e discussão da produção de trabalhos do estágio e principalmente de projetos terapêuticos singulares onde tem a oportunidade de realizar dispositivos de gestão e de atenção da clínica especializada ampliada ${ }^{27}$.
Outro turno semanal é também reservado para as atividades de tutoria ${ }^{26}$, com o objetivo de permitir reflexões mais aprofundadas e individualizadas. Para isso, articulam-se as modalidades de ensino presencial e à distância, possibilitando acompanhar e orientar a atuação do aluno no campo de formação específico. Nas atividades de educação à distância utiliza-se o ambiente virtual de aprendizagem da plataforma Moodle. Na tutoria presencial os alunos são organizados em grupos menores, de acordo com os campos de estágio em que atuam ${ }^{13}$.

Para o levantamento e acompanhamento das opiniões dos estagiários sobre as experiências vivenciadas no estágio, elaborou-se um instrumento de pesquisa em forma de questionário escrito e estruturado, composto por questões abertas e fechadas sobre os assuntos a serem avaliados. O questionário possui 32 perguntas organizadas em cinco blocos temáticos: Bloco I - Identificação; Bloco II - O agir em competência para atenção especializada em saúde bucal. Bloco; III - Avaliação dos campos de estágio; Bloco IV - Atividades de educação a distancia; e Bloco V - Avaliação pedagógica. O instrumento foi hospedado na plataforma Google Docs por meio de uma ferramenta que permitiu que as respostas obtidas fossem sendo armazenadas no Google Drive em forma de uma planilha possível de ser exportada para o programa Excel 2000 (Microsoft). Os estagiários responderam o questionário entre os dias 13/06 a 03/07/2013, após terem sido finalizadas todas as atividades curriculares pertinentes aos estágios.

Os dados foram analisados pela frequência das respostas fechadas. As questões abertas foram analisadas com base nos fundamentos da análise do discurso, em que se objetivou alcançar o sentido e não apenas o conteúdo do texto ${ }^{28}$. Buscou-se compreender 
o que elas revelavam em relação às questões fechadas em relação ao referencial teórico utilizado e sobre o conceito de competências e do agir em competência ${ }^{15}$.

Este artigo apresenta-se como resultado da primeira etapa do projeto de pesquisa intitulado Estágio Curricular em Serviços de Gestão e de Atenção Especializada em Saúde Bucal no SUS, entre os anos de 2012 e 2014, submetido à aprovado pelo Comitê de Ética da UFRGS através da Plataforma Brasil com o número CAAE 08575312.0.0000.5347.

\section{RESULTADOS}

Os 31 estagiários que cursaram o Estágio Curricular Supervisionado II da Odontologia no primeiro semestre de 2013 responderam ao questionário. O perfil dos entrevistados compõe-se de $77 \%$ do sexo feminino e $23 \%$ do masculino, com uma idade que variou de 22 a 29 anos. Todos relataram estarem solteiros. A maioria (94\%) é do estado do Rio Grande do Sul e 51\% e reside em Porto Alegre.

\subsection{O agir em competência para atenção especializada em saúde bucal}

A Tabela 1 apresenta os resultados gerais avaliados pelos estagiários segundo categorias temáticas originadas do questionário: protocolos, campos de estágio, atividades de educação à distância e dinâmicas pedagógicas. A análise da relação entre as respostas fechadas (Tabela 1) e as abertas (observações subjetivas dos alunos sobre cada categoria temática) será apresentada a seguir, permi- tindo compreender com maior profundidade sobre o processo de produção do agir em competência para atuar na atenção especializada em saúde bucal.

\subsection{Protocolos}

Nesta categoria temática, de um modo geral, quatro itens avaliados obtiveram respostas posicionadas com mais frequência no escore ótimo/muito bom e apenas dois como bom/regular (Tabela 1).

\section{A motivação para o trabalho no}

SUS foi o componente analisador da categoria com maior frequência de respostas no escore ótimo/muito bom (77\%) (Tabela 1). Quando solicitados a descrever de forma aberta, os estagiários apontam como pontos positivos a experiência e o aprendizado sobre o funcionamento da atenção especializada da saúde bucal no sistema de saúde, destacando que apesar de problemas, na maioria das vezes ele é resolutivo e eficaz. Consideram a possibilidade de continuar trabalhando na área, lembrando que outros fatores influenciariam sua decisão, tais como carga horária, salário e plano de carreira satisfatórios.

"Trabalhar na atenção especializada foi estimulante. Antes de entrar no sistema considerava o trabalho na atenção secundária limitante, monótono. Atuando na prática foi possível perceber o aspecto desafiador deste trabalho, o dinamismo da rotina na atenção secundária, o que me deixou muito estimulada para continuar trabalhando nesta área (Estudante 08)”. 
Tabela 1 - Distribuição da frequência de respostas segundo categorias temáticas e seus componentes analisadores

\begin{tabular}{|c|c|c|c|c|c|}
\hline Protocolos & $\begin{array}{c}\text { Ótimo/ } \\
\text { Muito Bom n } \\
(\%)\end{array}$ & $\begin{array}{c}\text { Bom/ } \\
\text { Regular } \\
\text { n (\%) }\end{array}$ & $\begin{array}{c}\text { Insatisfatório } \\
\text { n (\%) }\end{array}$ & $\begin{array}{c}\text { Não } \\
\text { Sabe } \\
(\%) \\
\end{array}$ & $\begin{array}{l}\text { Total } \\
\text { n (\%) }\end{array}$ \\
\hline Conhecimento dos protocolos & $15(48)$ & $16(52)$ & $0(0)$ & $0(0)$ & $31(100)$ \\
\hline Inserção na realidade & $22(71)$ & $8(26)$ & $1(3)$ & $0(0)$ & $31(100)$ \\
\hline Aplicação de protocolos & 12(39) & $18(58)$ & $0(0)$ & $1(3)$ & $31(100)$ \\
\hline Motivação & $24(77)$ & $6(19)$ & $0(0)$ & 1(3) & $31(100)$ \\
\hline Respeito aos valores técnicos & $19(61)$ & $11(36)$ & $0(0)$ & $1(3)$ & $31(100)$ \\
\hline Trabalho em equipe & $17(55)$ & 11(35) & $1(3)$ & 2(6) & $31(100)$ \\
\hline \multicolumn{6}{|l|}{ Campos de estágio no SUS } \\
\hline Campos Assistência & $24(78)$ & $6(19)$ & $0(0)$ & 1(3) & $31(100)$ \\
\hline Campos Gestão & $7(23)$ & $16(51)$ & $8(26)$ & $0(0)$ & $31(100)$ \\
\hline CEO UFRGS & $26(84)$ & $5(16)$ & $0(0)$ & $0(0)$ & $31(100)$ \\
\hline Preceptor & $23(74)$ & $7(23)$ & $1(3)$ & $0(0)$ & $31(100)$ \\
\hline Estrutura & 20(65) & $10(32)$ & $1(3)$ & $0(0)$ & $31(100)$ \\
\hline \multicolumn{6}{|c|}{ Atividades de educação à distância } \\
\hline Atividades EAD & $15(48,5)$ & $13(42)$ & $2(6,5)$ & $1(3)$ & $31(100)$ \\
\hline MOODLE & $17(54)$ & $14(46)$ & $0(0)$ & $0(0)$ & $31(100)$ \\
\hline Conteúdos & $23(74)$ & $8(26)$ & $0(0)$ & $0(0)$ & $31(100)$ \\
\hline Fóruns EAD & $20(64)$ & $6(20)$ & $5(16)$ & $0(0)$ & $31(100)$ \\
\hline \multicolumn{6}{|l|}{ Dinâmicas pedagógicas } \\
\hline Planejamento Pedagógico & 11(36) & $17(55)$ & $1(3)$ & $2(6)$ & $31(100)$ \\
\hline Objetivos & 25(80) & $6(20)$ & $0(0)$ & $0(0)$ & $31(100)$ \\
\hline Atividade presencial & $15(48)$ & $16(52)$ & $0(0)$ & $0(0)$ & $31(100)$ \\
\hline Docentes & $22(71)$ & 9 (29) & $0(0)$ & $0(0)$ & $31(100)$ \\
\hline Tutoria & $5(16)$ & 23(74) & $3(10)$ & $0(0)$ & $31(100)$ \\
\hline Projetos terapêuticos & $19(61)$ & $12(40)$ & $0(0)$ & $0(0)$ & $31(100)$ \\
\hline Conteúdos & $18(58)$ & $13(42)$ & $0(0)$ & $0(0)$ & $31(100)$ \\
\hline Relações realidade & $19(62)$ & $11(35)$ & $1(3)$ & $0(0)$ & $31(100)$ \\
\hline Carga horária & $20(64)$ & $10(33)$ & $1(3)$ & $0(0)$ & $31(100)$ \\
\hline
\end{tabular}

Inserção na realidade foi o segundo componente melhor avaliado pelos estagiários (71\%). Destacam nas respostas abertas como é importante a vivência da dinâmica no SUS em seus variados níveis de atenção. A aquisição de habilidades técnicas a respeito do funcionamento da rede de atenção especializada em saúde bucal também foi citada como positiva. Porém, a falta de autonomia foi observada. Destacam que gostariam de ter sido mais úteis em alguns momentos e indicam alguns aspectos como explicação para isso, tais como, o nível de complexidade clí- nico de determinadas situações da atenção especializada, a realização de muitos procedimentos característicos do nível primário de atenção e as dificuldades de conhecimentos e práticas a respeito do tema da gestão.

"O estágio possibilitou vivência em saúde secundária de forma dinâmica e demonstrativa. Foi possível ver na prática as dificuldades e os nós críticos que o sistema enfrenta assim como a própria articulação, ou mesmo a dificuldade de se organizar em rede. Hoje próximo ao fim do estágio pude ver o 
outro lado da moeda, pois antes na básica tinha uma visão do CEO e agora tenho outra e conhecimento dos problemas principais em ambos os níveis de atenção (Estudante 18)".

A avaliação dos componentes analisadores referentes ao respeito aos valores técnicos e ao trabalho em equipe na atenção especializada também obtiveram maior frequência de respostas no escore ótimo/muito bom, $61 \%$ e $54 \%$ respectivamente (Tabela 1 ).

Nas respostas abertas ao explicar sobre o respeito aos seus valores e opiniões técnicas os estagiários se dividiram. Uma parte salientou que são respeitados e possuem liberdade para atuar e exercer o aprendido no curso.

"Minhas sugestões e colocações foram acolhidas (Estudante 25)”. "Os profissionais trocavam ideias e tínhamos liberdade em questionar. Houve muito respeito mútuo. (Estudante 29)”.

Outros identificaram restrições à sua autonomia.

"A falta de alguns materiais dificultou, mas fiz um bom trabalho, só que diferente do aprendido na faculdade. (Estudante 09)". "Algumas vezes, precisei seguir o protocolo ou modo de atendimento seguido pelos profissionais $d a$ área, por questão de gosto do profissional, embora tenha aprendido de forma diferente (Estudante 7)".

Quanto ao trabalho em equipe, a avaliação dos estagiários aparece bastante vinculada ao local onde foi realizado o estágio. Muitos levantam o problema de não haver grande interação entre as especialidades e conversa entre os profissionais envolvidos entre si e com os usuários. Na maior parte dos serviços em que estagiaram afirmam não ser frequente a existência de reuniões de equipe.
"Acho que nesse âmbito há necessidade de melhorar muito, não observei conversas entre a equipe, discussão de casos, nem mesmo reuniões. $O$ atendimento nas diferentes áreas, na minha opinião, ainda é bem fragmentado (Estudante 7)".

Verifica-se que dois componentes importantes da categoria temática protocolos, relacionados com a aquisição de conhecimentos sobre protocolos de atenção especializada e a aplicação desses protocolos, obtiveram o maior número de respostas concentradas no escore bom/regular, 52\% e $58 \%$ respectivamente.

As falas abertas dos estagiários sobre o item conhecimentos dos protocolos denotam o intenso e complexo processo de aprendizagem que a experiência do estágio lhes proporcionou. Se por um lado reconhecem o período do estágio como um momento de aprendizagem teórica sobre os protocolos da atenção especializada no SUS, também salientam dificuldades e entraves para aplicá-los nas realidades de alguns campos. Os depoimentos demonstram que o estágio permite que os estagiários articulem aos seus conhecimentos técnicos as práticas clínicas dos preceptores que os acompanham.

"Considero que tive uma excelente base do funcionamento da atenção especializada, as aulas foram claras e objetivas, embora tenha observado na prática dentro dos campos, que muitas vezes há uma resistência no cumprimento dos protocolos de atendimento (Estudante 7)". "Na prática podemos tirar nossas próprias conclusões sobre $o$ $C E O$, podemos saber quais são os pontos fortes e quais são os fracos e assim, ter uma opinião mais fundamentada sobre o assunto (Estudante 10)”. 
Quanto à capacidade de aplicar os protocolos preconizados, nas respostas abertas, lembram os estagiários, que em algumas situações sentiram a necessidade de modificar os protocolos e que a vivência clínica no estágio os tornou aptos para saber quando aplicá-los e quando alterá-los.

\begin{abstract}
"Apesar de encontrar algumas dificuldades na aplicação dos protocolos, devido a certos desvios do sistema, acho que isso é apenas uma questão de adaptação. Como em tudo sempre haverá situação em que abriremos exceções, entretanto, de maneira geral, me senti capaz de cumprir os protocolos. (Estudante 7)". "Embora os protocolos estejam disponíveis e sejam necessários ao serviço, ainda há muita dificuldade de aplicá-los em alguns locais (Estudante 18)". “Acredito que não só sou capaz de aplicar, como sugerir modificações para buscar melhorias no serviço (Estudante 31)”.
\end{abstract}

No estudo também foi introduzida uma questão sobre se o estagiário durante o estágio nos serviços do SUS havia modificado os protocolos estabelecidos para a atenção especializada na saúde bucal, com $74 \%$ dos estagiários afirmando que sim. As explicações mais salientadas pelos entrevistados para justificar a quebra de protocolo foram quanto a constante necessidade de adaptação das diferentes realidades as condições de trabalho locais e as orientações dos preceptores. Na opinião dos estagiários a quebra de protocolos também ocorreu como uma forma positiva

"de priorizar o cuidado do paciente (Estudante, 33), ou para facilitar a vida do paciente, que muitas vezes não está em condições ideais para o atendimento especializado (Estudante 30)". "Modifiquei de modo que meu trabalho durante um tratamento não recebessem as desvantagens de aplicar um protocolo contendo a mecanização do exercício profissional, o engessamento da prática do cuidado e principalmente a limitação da autonomia (Estudante 29)”.

Os principais exemplos sobre quebra de protocolos citados como marcantes pelos estagiários foram: realizar procedimentos indicados para atenção básica na atenção especializada, tais como tratar candidíase, raspagem periodontal e restaurações simples; realizar procedimentos sem radiografia; realizar atendimentos de usuários sem referência da Unidade Básica de Saúde; em relação ao protocolo de acompanhamento dos usuários com tratamento especializado completado e encaminhar para serviços da Faculdade de Odontologia. A Seguir, algumas das situações relatadas pelos alunos:

“Um paciente atendido na área de periodontia tinha uma lesão na mucosa jugal, compatível com uma leucoplasia. Caso ele fosse referenciado para a UBS para depois consultar com o estomatologista ia demorar algum tempo. Por isso, achamos melhor encaminhar o mesmo para a disciplina de Patologia Bucal na FO-UFRGS, dando agilidade no atendimento (Estudante 23)". "Tanto nos campos de estágio fora da faculdade quanto dentro da faculdade, em muitos momentos tive que fugir dos protocolos, principalmente em relação à periodontia. Praticamente todos os pacientes que atendi na área de periodontia tive que fazer (ou refazer) todo o tratamento supragengival (Estudante 15)”.

\subsection{Campos de estágios no SUS}

A categoria temática campos de estágio no SUS apresenta as frequências de respostas fechadas que representam as opiniões 
dos estagiários sobre os preceptores, estrutura e campos onde foram realizados os estágios. A maioria das respostas sobre os componentes avaliados apresentam o processo como ótimo/muito bom. Estas opiniões só se modificaram substancialmente no item referente ao estágio nos campos de gestão, em que $56 \%$ dos estagiários responderam como bom/regular e $26 \%$ como insatisfatório (Tabela 1).

Os estagiários referem um bom acolhimento por parte dos campos de assistência Pontuam de maneira muito positiva a experiência, com possibilidades de aperfeiçoamento da prática clínica e aprendizagens sobre a atenção especializada no SUS, o ritmo de trabalho fora da faculdade, assim como, a dinâmica de trabalho dentro de um bloco cirúrgico.

\begin{abstract}
"Proporcionaram-me o contato com o serviço de atenção secundária e em âmbito hospitalar, oportunidade que antes não era desenvolvida por esta faculdade. $O$ saber adquirido com os casos complexos e únicos somaram de maneira muito positiva para a formação do conhecimento. A possibilidade de observar e praticar em bloco cirúrgico junto a um professor são oportunidades singulares dentro do nosso aprendizado (Estudante 31)". "Gostei muito dos campos de estágio que escolhi para trabalhar. Acredito que obtive uma vivência extremamente importante; além de aprender como funciona o dinamismo do SUS e como atender pacientes com casos mais complexos, coloquei em prática muitos conteúdos a respeito de diagnóstico e conduta, que apenas havia estudado na teoria (Estudante 27)"
\end{abstract}

No âmbito dos campos de gestão alguns estagiários relatam insatisfação com o trabalho que lá realizaram, visto que nas suas opiniões não há ainda adequação para o recebimento dos estagiários para o estágio, o que acaba por tornar o tempo algumas vezes ocioso e de pouco aprendizado. Este foi o item que obteve o maior índice de respostas no escore insatisfatório observando a pesquisa como um todo.

"Acho a ideia (de estágio na gestão) excelente, precisamos de uma vivência nessas áreas, para entender melhor quais são os principais entraves e desafios que podemos encontrar, como funciona o sistema, etc. Porém, os campos de estágio, pelo menos o que trabalhei, ainda não estão preparados para receber os alunos, acabamos em muitos momentos ficando ociosos $e$ quando nos é dado uma tarefa esta é superficial e vaga (Estudante 7)”. No campo em que estagiei, juntamente com meus colegas, pudemos trabalhar com instrumentos de avaliação dos serviços prestados e também com a elaboração de material informativo para os usuários, sendo bastante proveitoso (Estudante 7)".

A respeito dos estágios no CEO da FO-UFRGS a opinião foi positiva, compreendem como um estágio proveitoso do ponto de vista do nível de qualidade técnica do aprendizado. Um ponto também salientado como positivo é que são os próprios estagiários que escolhem as especialidades em que querem atuar, isso auxilia na boa realização do trabalho, pois em geral são áreas nas quais eles pretendem trabalhar futuramente.

"O CEO da faculdade é excelente, realizamos o trabalho com excelência clínica, sempre com maior possibilidade de aprendizado prático e teórico, pois temos ao lado ótimos professores e, 
além disso, temos mais autonomia nas tomadas de decisão (Estudante 7)”.

De maneira geral os preceptores dos estágios foram descritos como profissionais receptivos, prestativos, de bom convívio e excelentes orientadores.

Sobre a estrutura dos campos as opiniões foram diversas e dependiam do local onde havia sido realizado o estágio, porém em sua maioria os estagiários relataram que os campos possuem boa estrutura, mas que muitas vezes faltam instrumentais e a manutenção de equipamentos deixa a desejar.

\subsection{Atividades de educação à distância}

A Tabela 1 descreve também os resultados sobre as atividades de educação à distância realizadas no estágio. Todos os componentes destacados na pesquisa para avaliar este assunto obtiveram boa frequência de respostas no escore ótimo/muito bom.

Os estagiários de maneira geral acreditam que as atividades de educação à distância enriqueceram o conhecimento e tornaram seu acesso mais fácil, "garantido uma continuação e complementação das atividades nos campos" (Estagiário 33). Visto que no último semestre dispõem de pouco tempo para aulas convencionais a internet tornou mais fácil o contato com opiniões dos colegas e professores.

"Muitas vezes a falta de tempo e a fadiga do aluno não permite que ele em uma aula consiga desenvolver tão bem um tema proposto e na educação a distância permite que ele desenvolva melhor os temas $e$ inclusive identificar o pensamento dos mais tímidos (Estagiário 18)”.

Sobre o uso da plataforma Moodle no estágio, relatam bom uso da ferramenta. Facilita o aprendizado e a comunicação com os professores. A respeito dos conteúdos curriculares disponibilizados consideram em sua maioria como conteúdos bons e que o ambiente virtual de aprendizagem

"facilita o acesso às informações, pois estas ficam disponíveis e compiladas todas no mesmo lugar, podendo ser acessadas de qualquer local que tenha internet disponível (Estagiário 7)”.

De maneira geral os estagiários acreditam que os fóruns EAD realizados foram importantes para promover debates e expor diferentes pontos de vista entre os estagiários. Defendem que foi uma estratégia que ajudou a compor uma noção mais crítica a respeito dos assuntos. Mas, é preciso destacar que o item fóruns EAD obteve um índice de respostas no escore insatisfatório que se destacou quando comparado com os resultados da pesquisa como um todo.

\subsection{Dinâmicas pedagógicas adotadas no estágio \\ Na Tabela 1 encontram-se expostos} os resultados da opinião dos estagiários a respeito do planejamento das atividades pedagógicas desenvolvidas no estágio. Os resultados descritos mostram um desenho da categoria que se assemelha com as categorias analisadas anteriormente, pois as respostas ficaram aqui também distribuídas com maior freqüência no escore ótimo/muito bom.

Nas respostas abertas, quanto aos itens planejamento gerais das atividades pedagógicas e objetivos do estágio, um número pequeno de estagiários se manifestou. Os depoimentos que se repetiram afirmando que o planejamento foi organizado e que os objetivos do estágio foram alcançados.

"Sim, acho que sairemos com uma formação diferenciada, voltada para o 
serviço público, focada no atendimento de excelência, mas, principalmente focada no usuário e na realidade a qual ele se enquadra (Estagiário 7)”.

Houve sugestões para que houvesse mais preceptores ou convidados participando das atividades presenciais.

Quando perguntados sobre sua opinião a respeito das atividades presenciais na Faculdade de Odontologia da UFRGS os estagiários responderam que nesses encontros foi possível conhecer melhor os campos de estágio dos colegas, assim como, os desafios que todos enfrentavam, discutindo entre eles e com os professores a respeito dos problemas e possíveis soluções para os mesmos.

"Foi proporcionado bastante espaço para a turma interagir durante as aulas, sempre foi solicitado nossa opinião durante as aulas (Estagiário 14)”.

Em relação aos docentes do estágio os descrevem como interessados em repassar o conhecimento com didática e qualidade.

"Os docentes desenvolveram bem o conteúdo das aulas (Estagiário 11). Bem preparados, possuem bastante conhecimento da área (Estagiário 14)”.

Os momentos tutoriais aparecem nas respostas fechadas avaliados com maior frequência no escore bom/regular e com um índice de respostas no escore insatisfatório. Nas respostas abertas, os alunos explicam importância de poder expor ao seu tutor seus problemas e dúvidas, porém da forma como foram realizadas não compreenderam como:

"resolutivas na maioria das vezes (Estagiário 2)". "É um momento interessante para que o tutor tenha conhecimento do que se passa com os alunos nos campos estágio e para que o aluno peça ajuda quando necessário (Estagiário 7)". "Acho que poderia ter sido mais explorada, em grupos muito grandes, fica mais difícil conversar (Estagiário 14)”.

\section{Os Projetos Terapêuticos Singula-} res desenvolvidos pelos estagiários a partir de situações clínicas ou coletivas vivenciadas nos campos foi uma atividade avaliada pelos estagiários positivamente, $61 \%$ optaram pelo escore ótimo/muito bom. Os estudantes aprovam a ideia dos Projetos Terapêuticos Singulares. Citam o fato de que os trabalhos expostos pelos colegas foram bons de assistir, mostraram a teoria na prática e

"oportunidade excelente para trabalhar de forma integral e conjunta com os profissionais dos campos de estágio, a respeito de casos complexos (Estagiário 33)”.

Em geral, os estudantes consideram a relação com a realidade dos conteúdos teóricos desenvolvidos nos momentos presenciais com temas atuais e fundamentais para a sua formação, porém às vezes também cansativos.

"Certamente consegui relacionar o conteúdo com a realidade" (Estudante 9)".

Com relação à carga horária, os alunos a consideraram importante para o aprendizado.

"Tinha certos receios de como seria ser dentista fora da faculdade, e a vivência no estágio me ajudou bastante a adquirir essa noção (Estudante 11)”.

\section{DISCUSSÃO}

Os resultados apresentados analisam a capacidade em proporcionar o agir em competência para o cuidado especializado na saúde bucal de uma experiência de integração ensino-serviço na configuração de está- 
gio curricular supervisionado. Neste aspecto, um dado importante levantado pelo estudo, refere-se ao alto índice de respostas positivas quanto à questão da modificação de protocolos. Ao descreverem sua atuação no estágio, $74 \%$ dos estagiários afirmaram que modificaram os protocolos estabelecidos para o trabalho na atenção especializada em Odontologia. Considerando este resultado a luz do que preconiza o conceito do "agir em competência”, entende-se que a experiência das quebras de protocolos não deve ser compreendida como um aspecto negativo per si, pelo contrário. Na perspectiva ergológica desenvolvida pelo autor do trabalho enquanto uma atividade humana, vive-se um processo contínuo de renegociação de normas. Cada ser humano em uma situação de trabalho recompõe, em parte, o meio de trabalho em função do que ele é e do que ele desejaria que fosse o universo que o circunda. Em uma situação de trabalho a atividade é sempre o centro da dialética entre o impossível e o "invívivel"15. O estágio desenvolvido como experiência de integração ensino serviço deve desenvolver no estagiário justamente sua capacidade de gerir o inédito sempre presente em situações de trabalho, quando o profissional é remetido a tomar as suas decisões.

As informações aqui analisadas demonstram consonância com as de estudos sobre educação odontológica realizados em outros países, que também descrevem o impacto de experiências de integração ensino serviço sobre a aprendizagem de estudantes de Odontologia. Segundo esses estudos, os estudantes que participaram de processos de formação em que se enfatizam a integração ensino-serviço, demonstram maior consciência da importância dos determinantes sociais no processo saúde-doença ${ }^{29}$ e da importância de se compreender o histórico sócioodontológico $^{30}$. Além de adquirirem maior confiança na realização dos mais diversos procedimentos da cínica odontológica ${ }^{31,32}$. Currículos com programas de integração ensino serviço permitem aos estudantes um melhor entendimento das necessidades da comunidade $^{33}$.

Prevalece nos resultados do estudo a opinião de que houve aperfeiçoamento da capacidade dos estagiários em realizarem atividades clínicas especializadas. Resultados esses, similares aos encontrados por outros estudos sobre experiências de ensino odontológico realizadas em estágios fora das universidades. Essas experiências têm se mostrado muito valiosas tanto em volume quanto em diversidade, contribuindo para a maturidade clínica dos estudantes ${ }^{34,35}$. Um estudo realizado com 55 estudantes da Universidade de Witwatersrand, África do Sul, avaliou suas percepções a respeito das experiências com integração ensino-serviço e encontrou que 95\% dos alunos reportaram melhoras em suas habilidades clínicas ${ }^{33}$. Reflexão é uma característica central da integração ensinoserviço em que o objetivo pedagógico não está apenas em aumentar os conhecimentos e habilidades clínicas dos alunos, mas em facilitar o seu desenvolvimento pessoal e profissional $^{13,20}$.

É preciso destacar que a implantação do Estágio Curricular Supervisionado II da Odontologia, objeto de análise desse estudo, foi acompanhada por incentivo financeiro do Ministério da Saúde através da adesão da instituição ao Programa Nacional de Reorientação da Formação Profissional em Saúde Pró-Saúde ${ }^{36}$. O financiamento do Pró-saúde foi incentivador fundamental para aumentar o interesse da instituição de ensino na implantação do estágio no SUS. Estudos em diversos países mostram uma preocupação crescente de reitores e membros docentes em relação ao impacto de programas de ensino- 
serviço nas finanças das Faculdades de Odontologia $^{22}$ e também com relação aos desafios em se estabelecer modelos de ensino que sejam financeiramente sustentáveis ${ }^{37}$.

Seria interessante poder avaliar em estudos futuros a produtividade de alunos que participam de experiências fora da instituição de ensino em comparação àquela alcançada com as atividades tradicionais realizadas no seu interior. Estudos mostram que a produtividade clínica dos estudantes é maior em experiências de ensino-serviço realizadas fora da instituição de ensino ${ }^{38,23}$. Esta informação pode ser relevante para que se desenvolva um entendimento da produtividade esperada e para a seleção daqueles locais que podem proporcionar as experiências clínicas mais ricas ${ }^{39}$. Um dos princípios da integração ensino-serviço é que suas atividades e objetivos sejam baseados tanto nos interesses de aprendizado quanto nas necessidades da comunidade a ser atendida. Deve haver benefícios equivalentes para ambas as partes, equilibrando serviço e aprendizado, sendo essa uma das principais características que diferencia a integração ensino-serviço de outras experiências com formatos similares ${ }^{13}$.

\section{CONSIDERAÇÕES FINAIS}

A partir dos resultados apresentados pelo artigo pode-se inferir que na percepção dos estagiários a experiência analisada está desenvolvendo aprendizagens sobre o funcionamento das redes de atenção em saúde bucal e o desenvolvimento de competências para a resolução de problemas.

Um resultado importante encontrado pelo estudo é a constatação da reincidente quebra de protocolos da atenção especializada em saúde bucal relatada pelos estagiários. Se este dado por um lado pode representar o nível ainda incipiente em que se encontra a política de atenção especializada em saúde bucal analisada, também é um desafio para a compreensão da própria dinâmica do trabalho em saúde e as complexas relações entre o que está prescrito e a realidade como se apresenta no dia a dia do trabalho em saúde. Autores do campo da ergologia têm desenvolvido estudos nesta direção que necessitam ser mais utilizados na pesquisa e na ação.

Os componentes da experiência que obtiverem maior índice de avaliação insatisfatória da experiência de integração ensinoserviço foram também aqueles com o maior potencial de inovação pedagógica e política: os campos de gestão, as tutorias e os fóruns de educação à distância. Isto indica que o ineditismo exige que se realize constante monitoramento da proposta e continuidade de pesquisas como estas, avaliando as turmas em andamento. É necessário que as análises sejam estendidas buscando informações sobre o processo também na perspectiva dos preceptores, tutores, docentes e gestores, não privilegiadas no presente estudo. Há necessidade de problematização permanente sobre as práticas de estágio e que se assegure infraestrutura e profissionais qualificados para o ensino nos serviços de saúde.

\section{REFERÊNCIAS}

1. Kress, Junior GC. Dental education in transition. In: Cohen LK, Gift HC. Disease prevention and oral health promotion social-dental sciences in action. Copenhagen: Munsksgaard; 1995 p. 387416.

2. Hobson RS. A view of European challenges in dental education. $\mathrm{Br}$ Dent $\mathrm{J}$. 2009 jan 24; 206(2):65-6.

3. Mcharg J, Kay EJ. Designing a dental curriculum for the twenty-fi rst century. Br Dent J. 2009 nov 28;207(10):493-7. 
4. Davidson PL, Nakazono TT, Carreon DC, Gutierrez JJ, Shahedi S, Andersen, RM. Reforming dental workforce education and practice in the USA. Eur J Dent Educ. 2011; 15(2):73-9.

5. Brasil. Ministério da Saúde. Ministério da Educação. Resolução CNE/CNS 3/2002. Diretrizes Curriculares Nacionais do Curso de Odontologia. Diário Oficial da União, Brasília, 4 de março de 2002. Seção 1, p.10, Brasília, 2002.

6. Moysés SJ. Políticas de saúde e formação de recursos humanos em Odontologia. Rev. ABENO. 2004;4(1):30-7.

7. Ramos MN. A pedagogia das competências: autonomia ou adaptação? 4. ed. São Paulo: Cortez; 2011. 320p

8. Silveira JLGC. Diretrizes curriculares nacionais para os cursos de Graduação em Odontologia: historicidade, legalidade e legitimidade. Pesq Bras Odontop Clín Int. 2004;4(2):151-6.

9. Zilbovicius C, Araujo ME, Botazzo C, Frias AC, Junqueira SR, Junqueira CR. A paradigm shift in predoctoral dental curricula in Brazil: evaluating the process of change. J Dent Educ. 2011;75(4):557-64.

10. Fewerwerker LM, Capozzolo AA. Mudanças na formação dos profissionais de saúde: alguns referenciais de partida do eixo Trabalho em Saúde. In.: Capozzolo AA, Henz AO, (Orgs.) Clínica Comum: itinerários de uma formação em saúde. São Paulo: Hucitec; 2013. p. 35-58.

11. Pucca Jr GA, Costa JF, Chagas LD, Silvestre RM. Oral health policies in Brazil. Braz Oral Res. 2009;23 Suppl 1:S9-16.

12. Pucca Jr GA, Luvison I, Baldisserotto J, Warmling CM. Política Nacional de Saúde Bucal: metas e resultados. Bol. Saúde (RS) 2010 jan/jun;24(1):117-26.
13. Warmling CM, Rossoni E, Hugo FN, Toassi RF. Estágios curriculares no SUS: experiências da Faculdade de Odontologia da UFRGS. Rev ABENO. 2011; 11(2), p. 63-70.

14. Brasil. Ministério da Saúde. Secretaria de Atenção à Saúde. Departamento de Atenção Básica. Manual de especialidades em saúde bucal. Brasília: Ministério da Saúde, 2008 (Série A. Normas e Manuais Técnicos).

15. Schwartz Y. Uso de si e competência. In Schwartz Y, Durrive L (Org.) Trabalho \& Ergologia: conversas sobre a atividade humana. Niterói: Eduff, 2007.

16. Yoder KM. A framework for servicelearning in dental education. J Dent Educ. 2006;70(2):116-22.

17. Mello ALSF, Moysés SJ, Carcereri DL. Ensino ou Serviço? A Universidade e o Curso de Odontologia na rede de atenção à saúde bucal. Mundo saúde. 2011;35(4):364-72.

18. Costa ICC, Araújo, MNT. Definição do perfil de competências em saúde coletiva a partir da experiência de cirurgiõesdentistas atuantes no serviço público. Ciên Saúde Colet. 2011; 16(Supl.1) p.1181-9.

19. Freitas SFT, Calvo MCM, Lacerda JT. Saúde coletiva e novas diretrizes curriculares em Odontologia: uma proposta para graduação. Trab Educ Saúde. 2012 jul/out;10(2):223-34.

20. Toassi RFC, Baumgarten A, Warmling CM, Rossoni E, Rosa AR, Slavutzky SMB. Teaching at primary healthcare services within the Brazilian national health system (SUS) in Brazilian healthcare professionals' training. Interface (Botucatu). 2013June; 17(45):38592. 
21. Grobe Hood, J. Reflections on the dental pipeline program's efforts regarding community-based dental education. J Dent Educ. 2010;74(10):S62-S66.

22. Bailit HL, Mcgowan TL. Senior dental students' impact on dental school clinic revenues: the effect of community-based dental education. J Dent Educ. 2011;75(10 SUPPL): p. S5-S7.

23. Smith M, Lennon MA, Robinson PG. Students' clinical experience on outreach placements. Eur J Dent Educ. 2010;14(1):7-11.

24. Formicola AJ, Bailit HL. Communitybased dental education: history, current status, and future. J Dent Educ. 2012;76(1):98-106.

25. Brasil. Lei $\mathrm{n}^{0} 11.788$, de 25 de setembro de 2008. Dispõe sobre o estágio de estudantes e dá outras providências. Diário Oficial da União, Brasília, 26 de set. 2008.

26. Botti SHO, Rego S. Preceptor, supervisor, tutor e mentor: quais são seus papéis? Rev Bras Educ Med. 2008 Sept;32(3):363-73.

27. Brasil. Ministério da Saúde. Secretaria de Atenção à Saúde. Núcleo Técnico da Política Nacional de Humanização. Clínica ampliada, equipe de referência e projeto terapêutico singular. 2. ed. Brasília: Ministério da Saúde, 2007. 60 p. (Série B. Textos Básicos de Saúde).

28. Caregnato RCA, Mutti R. Pesquisa qualitativa: análise de discurso versus análise de conteúdo. Texto Contexto Enferm. 2006 Out-Dez;15(4): 679-84.

29. Nandakumar C. Robinson PG. Teaching dental public health to undergraduates using community profiles and patient case studies. Community Dent Health. 2011;28(1):116-20.
30. Holmes RD, Waterhouse PJ, Maguire A, Hind V, Lloyd J, Tabari D, Lowry RJ. Developing an assessment in dental public health for clinical undergraduates attending a primary dental care outreach programme. Eur J Dent Educ. 2011 Feb;15(1):19-25.

31. Lynch, CD, Ash PJ, Chadwick BL. Student perspectives and opinions on their experience at an undergraduate outreach dental teaching centre at Cardiff: a 5year study. Eur J Dent Educ. 2010;14(1):12-6.

32. Smith M, Lennon MA, Brook AH, Robinson PG. A randomized controlled trial of outreach placement's effect on dental students' clinical confidence. J Dent Educ. 2006; 70(5):566-70.

33. Bhayat A, Vergotine G, YengopaL V, Rudolph MJ. The impact of servicelearning on two groups of south african dental students. J Dent Educ. 2011;75(11):1482-8.

34. Arantes AC, Pinto RS, Ramos TCV, Palmier AC. Estágio Supervisionado qual a sua contribuição para a formação do cirurgião-dentista de acordo com as diretrizes curriculares nacionais? Rev APS. 2009 abr/jun;12(2):150-60.

35. Eriksen HM, Bergdahl M, Byrkjeflot LI, Crossner CG, Widström E, Tillberg A. Evaluation of a dental outreach teaching programme Eur J Dent Educ. 2011;15(1):3-7.

36. Brasil. Ministério da Saúde. Ministério da Educação. Secretaria de Gestão do Trabalho e da Educação na Saúde. Programa Nacional de Reorientação da Formação Profissional em Saúde Pró-saúde. Brasília; 2005. Disponível em: http://www.saude.gov.br/sgtes Acesso em: 12 de abril de 2012. 
37. Piskorowski WA, Fitzgerald M, Mastey J, Krell RE. Development of a sustainable community-based dental education program. J Dent Educ. 2010;75(8):103843.

38. Perez FA, Allareddy V, Howell H, Karimbux N. Comparison of clinical productivity of senior dental students in a dental school teaching clinic versus community externship rotations. J Dent Educ. 2010;74 (10):1125-32.

39. Arevalo O, Sama NDM, Rohall V. Measuring clinical productivity in community-based dental education programs. J Dent Educ. 2011;75(9):1200-7.

\section{ABSTRACT \\ The competence to act in the specialized care in oral health care}

The aim of this study was to broaden the understanding of the role of the protocols in the production of an "act jurisdiction" to specialized care in oral health care. The methodological approach used qualitative and quantitative data. An online questionnaire with 32 questions structured into five thematic blocks was applied to the trainees to respond anonymously. Themes and components analyzers were systematized as: protocols, internship field, distance education activities and educational methods. Quantitative data were analyzed by frequency of closed answers. In relation to the open questions the objective was to analyze them deeply to achieve a sense, not only the text content. The results showed that the experience of learning-service integration is providing a meaningful learning about the operation of networks of specialized dental care and in the development of skills for solving problems. The modification of the specialized dental care protocols is a constant experience lived by the trainees in the fields of internship. The experience aspects with greater potential of either political or pedagogical innovation were the fields of management, mentoring and distance education. However they also exhibited the greatest weakness.

Descriptors: Oral Health. Education. Competency-based Education. Curriculum. Dental Education.

Correspondência para:

Cristine Maria Warmling

e-mail: cristinewarmling@yahoo.com.br

Rua Ramiro Barcelos, 2492 - Santa Cecilia 90035-003 - Porto Alegre/RS 